\title{
Application of Unit Commitment with Market Pool in a Peaking Power Generation Firm in the Philippines for a Cost Reduction Case Study
}

\author{
Luke Rey Santillan, ${ }^{1}$ Kenn Brylle Senen, ${ }^{1}$ Robert Wamilda Jr., ${ }^{1}$ Lanndon Ocampo, ${ }^{2}$ \\ Rafael Seva Jr., ${ }^{3}$ Reuella J. Bacalso, ${ }^{4}$ and Alaine Liggayu ${ }^{1}$ \\ ${ }^{1}$ Department of Industrial Engineering, University of San Carlos, 6000 Cebu, Philippines \\ ${ }^{2}$ Department of Mechanical and Manufacturing Engineering, University of San Carlos, 6000 Cebu, Philippines \\ ${ }^{3}$ Department of Electrical and Electronics Engineering, University of San Carlos, 6000 Cebu, Philippines \\ ${ }^{4}$ Department of Mathematics, University of San Carlos, 6000 Cebu, Philippines \\ Correspondence should be addressed to Lanndon Ocampo; laocampo@usc.edu.ph
}

Received 15 November 2015; Revised 22 February 2016; Accepted 15 March 2016

Academic Editor: Ashish Goel

Copyright ( 2016 Luke Rey Santillan et al. This is an open access article distributed under the Creative Commons Attribution License, which permits unrestricted use, distribution, and reproduction in any medium, provided the original work is properly cited.

\begin{abstract}
This paper attempts to provide an optimum loading schedule of power generating units with the least cost by solving a unit commitment (UC) problem and to present good estimates of cost differences when UC problem is not applied. UC is a fundamental optimization problem of power generation systems which determines the optimum schedule of generating units which minimizes generation costs. However, for small power generation firms which are situated in developing countries, UC-based problems are poorly understood if not implemented and the scheduling of generating units is based on some methodologies which may provide results that are not optimal. Thus, a case study in a small power generation firm in central Philippines is carried out to elucidate these objectives. The case requires a solution of the mixed-integer nonlinear programming (MINLP) problem. Results show that the proposed UC-based problem yields optimal costs and the cost disparity from the current scheduling scheme is approximately at $27 \%$ which may be considered as potential cost savings. This shows that UC-based problem provides a reliable platform in achieving minimal generation costs. These results are significant to decision-makers particularly in small power generation firms and to engineering practitioners in the Philippines and in some developing countries as these provide an overview of the disparity of cost figures of not implementing UC.
\end{abstract}

\section{Introduction}

In power generation systems, unit commitment (UC) optimization problem is vital in solving a basic level dispatch decision [1]. UC is considered as a complex optimization problem that determines the load of each power generation unit satisfying the load demand of the generation system in a specified planning horizon. Its complexity is further enhanced by special constraints that conform to some system and physical conditions [2] such as meeting emission limits, addressing market requirements, and incorporating renewable energy sources. The main objective of the basic $\mathrm{UC}$ is to minimize total generation costs while meeting system requirements. The form of the constraints of the basic UC resembles largely the constraints of the widely known economic load dispatch (ELD) problem which is comprehensively discussed in domain literature [3]. The main departure of UC from ELD is the output production plan and schedule for a specified time interval or planning horizon, for example, daily, weekly, and monthly.

Due to the complexity of the UC problem not to mention its nonlinear property, various techniques have been proposed to address certain issues. The complex behavior of UC has challenged many domain scholars in solving the optimization problem. Some of these classic but plausible techniques include the priority list method [4] and 
Lagrangian relaxation method [5]. These techniques however encounter problems in obtaining feasible solutions and the time needed to obtain global optimal values is generally long. Following this difficulty, conventional and metaheuristic approaches are recently used to address various extensions of UC or ELD such as the mixed-integer linear programming (MILP) model [6] and differential evolution model [7]. Each of these approaches has its own corresponding strengths and limitations. As of the time being, there is no dominant approach that addresses majority of the UC or ELD problem and its extensions.

Over a decade and a half ago, state regulations of various countries have driven power generation industries from the monopolistic characteristics to competitive wholesale markets. This intensifies competition among firms in the industry and survival depends primarily on the costs required in their power generation process. Competition is introduced through a spot market entity that acts as a poolbased electricity market. Following this market competition, power generation firms need to produce electricity at the least possible cost. In advanced knowledge-based economies, this dilemma is basically addressed by solving UC or ELD problems and the cost minimization approach lies on the selection of power generating units that have good fuel consumption profiles. However, the same is not true in developing countries particularly in small power generation systems where UC or ELD problems are rarely understood and implemented. The dilemma of cost minimization is evidently rooted from the arbitrary loading plan because of not implementing the UC problem. Thus, this work attempts to present a case study of implementing a UC problem in a power generation firm situated in a developing country, that is, the Philippines. The objective of this work is twofold: (1) to address the generation cost minimization problem by way of solving a UC problem and (2) to document and present some good estimates on the cost differences of actual versus hypothetical costs generated from the use of the UC problem. This paper is significant for engineering practitioners in developing countries such as the Philippines as it provides them an overview of cost disparities of not implementing the UC model in power generation industries. A case study is implemented in a small peaking power generation firm in central Philippines. The case firm, due to its size, has the option of purchasing power from the market. This constraint is added in the basic UC problem. The contribution of this work is in implementing the UC problem in a small power generation firm in a developing country and in documenting estimates of possible cost reduction following the use of UC.

\section{Literature Review}

2.1. Unit Commitment. Raju et al. [1] described a unit commitment problem (UC) as an elementary level scheduling process of power systems. While economic load dispatch (ELD) assumes that all generating units are online, UC determines which units to dispatch, start up, shut down, ramp up, or ramp down. UC typically answers the problem "Given that there are a number of subsets of the complete set of $N$ generating units that would satisfy the expected demand, which of these subsets must be used in order to provide the minimum operating cost?" [8]. UC is more applicable for peaking plants since generating units of these plants are not usually online all the time. UC focuses on scheduling generating units to meet the forecasted load demand over a time period or planning horizon under different operational constraints [9]. Its prime objective is to reduce total generation costs particularly fuel costs [1]. With the UC problem, ELD becomes a subproblem. Sendaula et al. [10] developed a model that attempts to solve the UC problem and ELD problem simultaneously. UC is also used to determine current electrical resources to fulfil the load demand and allocate margin of operating reserve over a considerable amount of time [11]. UC problems are usually modelled as mixed-integer nonlinear programming (MILP) problems with a number of binary variables [8]. Bakirtzis et al. [12] proposed a model that can produce a planned schedule of generation units with consideration on the ex ante price. The model also has the capability to generate a unit commitment and economic dispatch schedule for a 24-hour look-ahead schedule.

With the deregulation of the power generation industry and the introduction of the power market pool, UC and ELD have been transformed to address the growing need of having minimal generation costs in order for power generation firms to be market competitive $[13,14]$. These two models have incorporated bilateral contracts in their objective function. This enables production requirements to match customer demands. These models aim to determine prices for each bid [14]. Heredia et al. [13] developed a unit commitment model with considerations of bilateral contracts in their model. They also developed constraints that produce bidding strategies for a generating firm's participation in a market pool. Furthermore, they also looked into the selling of excess energy to the market pool. The electricity spot market is where power producers bid their production capacity to potential buyers [13]. The process of bidding and purchasing is defined as providing an energy block with corresponding price per bidding interval. Also power generation firms have to define the demand of their customers per bidding interval and the capacity firms are willing to generate. A considerable number of scholars have studied well UC with considerations of participating in a market pool, may it be a price taking or price making generation firm.

UC problems also have expanded to the scheduling not only of generating units but also of the maintenance of these units $[15,16]$. Furthermore, UC problems have also expanded to include the probability of the generating units to break down [17]. These extensions are effective in determining the chance of failure of the generating units and the scheduling of these units. This is useful in both UC and ELD problems since generating units experience wear and tear which entail corresponding costs [18-20].

\subsection{Extensions on the Basic Unit Commitment Problem. The} following subsections present some key emerging extensions of the basic UC problem. Note that the list is not intended to be exhaustive. 
2.2.1. Economic Emission Dispatch. Power generating firms emit harmful pollutants that contribute to global warming which affects all inhabitants [21]. Regulations in some countries require power plants to generate power at a tolerable level [22]. There have been a lot of approaches to solve this issue, namely, installing emission control equipment in power plants, switching to low sulfur coal, replacing aged fuel burner with newer ones, fuel switching, and emission dispatch [23]. Emission dispatch has been the ideal one due to its minimal capital requirement and ease of implementation [24]. The economic emission dispatch now focuses on minimizing emission and total fuel costs while still meeting different system requirements. It is a multiobjective nonlinear constrained optimization problem [22]. A lot of studies allocate different weights for each of the objective functions and selecting from a Pareto-optimal solution set based on the decision-maker's preference [23]. However, Granelli et al. [25] reduced the problem into a single objective function by considering emission as one of its constraints within an acceptable limit.

2.2.2. Sustainable Economic Dispatch. Sustainable production has been one of the many current environmental issues due to the diminishing of fossil fuel sources. To address this issue, power generation firms have leaned on renewable energy sources as a means to produce power [26]. However, most large storage systems rely on a mix of conventional and renewable sources due to its unpredictability in nature [27]. The probabilistic nature of these generating units has challenged many domain researchers to model its cost function. Some studies force the model to impose fuzzy logic in analyzing the uncertainty of these units [28]. Another approach addresses the complex behavior of these models using mixed-integer linear programming model [12].

2.2.3. Demand Induced Dispatch. The conventional power system runs their generator in a "load-flowing" manner and the supply-side of the equation is given most of the time an emphasis [29]. It is assumed that the demand side, which is the other side of the equation, is constant in the day ahead scheduling processes [30]. Capacity shortages, however, are not taken into account during peak hours. This issue was addressed by building more power plants that would be underutilized during lean hours just to satisfy the demands during the peak hours [30]. The issue was addressed through a remarkable approach which is the demand induced dispatch. In the demand induced dispatch approach, customers are expected to be flexible and should meet a unanimous decision with the supplier whether to reduce load and shift the load and by consumption mode switching [29]. Load shifting only changes the time of the day when the load is switched but the total demand of the day remains the same as emphasized by Papaioannou et al. [31].

The change in electric usage by end-use customers to their usual consumption rates is addressed through demand response models [32]. It can be either instantaneous or prescheduled [33] in order to answer the instability of electricity prices, incentives designed to induce lower electricity use at peaking hours, high market prices, and system's reliability [32]. The models are considering prices of power at short intervals making it interesting. Also, these models look over the capabilities of the power generation market that anticipates hourly demand $[34,35]$. Those who distribute or regulate electricity to improve better manageability to system operators and optimize their role in power systems and those who maximize revue for the providers used this models as stressed by Magnago et al. [33]. There are two classifications of the extensive categories and those are emergency and economic. Then the balance of supply and demand becomes a major concern; emergency models are allocated while on the other hand economic models are more voluntary to reduce potential demand if compensation is just.

2.2.4. Distributed Generation. One of the problems of large power grids is the high cost of transporting fuel and incorporating generating units that are far from the grids. Due to that, remote areas far from the grid were not provided with reliable and affordable power. The creations of smaller scale generating units which are the "microgrids" are the only seen solution. To address this issue, distributed energy is generated and stored by a number of small scale "microgrids," self-contained power plants which are controlled by large power grids but are located near to the load they provide [36]. Microgrids entail higher cost than conventional sources because they usually run on renewable energy sources and that would mean zero emission to the environment [37]. Safdarian et al. [38] said that microgrids contain a higher risk due to uncertainties but are integrated with demand response models to curtail power demand easily. However, Kayal et al. [37] disputed that distributed generations will have a large impact on innovations of power system structures because it provides eco-friendly, dependable, and cost-effective electricity to consumers. Thus, distribution companies are giving ample time to improve power quality while maximizing the benefits leading to reasonable bill payments.

While the preceding extensions, from Section 2.2.1 to Section 2.2.4, address specific issues that can be integrated in the classical UC problems, little or no information is available on quantifying the expected benefits of using the UC optimization problem especially in peaking power plants situated developing countries where unfamiliarity of the UC optimization model is dominant. Moreover, following the case condition, purchasing power from the market is integrated into the classical UC problem by treating it as a separate power generating unit with known cost figures. This situation is not well addressed in current literature. These two issues are the main departure of this work.

\section{Model Formulation}

The following notations are used in this section:

$F_{i}\left(P_{i}\right)$ : cost rate function of generator $i$ (in monetary unit, e.g., Php).

$P_{i}^{t}$ : load of the generator required at interval $t$ (in MW). 
$a_{i}, b_{i}, c_{i}$ : constants of the cost function $F_{i}\left(P_{i}\right)$.

$P_{D}$ : total system demand (in MW).

$P_{L}:$ internal consumption (in MW).

$P_{\min , i}:$ minimum capacity of generator $i$ (in $\mathrm{MW}$ ).

$P_{\max , i}:$ maximum capacity of generator $i$ (in $\mathrm{MW}$ ).

$U_{i}^{t} \in\{0,1\}$ : commitment state of generator $i$ at interval $t$.

$P_{i}^{t-1}$ : previous hour power generation of generator $i$.

$\mathrm{DR}_{i}$ : down ramp rate of generator $i$.

$\mathrm{UR}_{i}$ : upper ramp rate of generator $i$.

$r_{i}$ : available spinning reserve of generator $i$.

SP: spinning reserve needed to be available.

Due to the close relevance of UC and ELD problems, ELD problem formulation is first presented in this section. Given that there is $N$ number of generating units with cost rate $F_{i}$ (cost per MW) and output of $P_{i}(\mathrm{MW})$, the cost of generation for unit $i$ is the product of $F_{i}$ and $P_{i}$. The total generation cost of a plant with $N$ generating units is $F_{T}$. The objective is to minimize $F_{T}$. Hence the objective function can be written as

$$
\min F_{T}=\sum_{i=1}^{N} F_{i}\left(P_{i}\right)
$$

The cost rate $F_{i}$ is known to be a polynomial function with a degree that needs to be computed by way of curve fitting or regression analysis. The cost rate is taken from the gross input and net output curve of the generating unit. The input is defined as the total expense of the unit-fuel consumption and usually includes labour cost, among others. The output of the unit is the total power generated by the unit in terms of megawatt (MW) unit. $F_{i}\left(P_{i}\right)$ can be represented as a seconddegree polynomial

$$
F_{i}\left(P_{i}\right)=a_{i} P_{i}^{2}+b_{i} P_{i}+c_{i} \quad \forall i
$$

where $a_{i}, b_{i}$, and $c_{i}$ are constants of the cost function which can be determined using curve fitting techniques. The nature of the second-degree polynomial shown in (2) is discussed by [8].

In the basic ELD formulation, the constraints of the optimization model consist of the energy balance and the capacities of the power generation units. The energy balance is defined as the total generation is equal to the sum of the total system demand $\left(P_{D}\right)$ and the system loss $\left(P_{L}\right)$. The power balance constraint is transformed into

$$
P_{D}+P_{L}=\sum_{i=1}^{N} P_{i}
$$

where $P_{D}$ is the demand output of the firm, $P_{L}$ is the system loss to be incurred, and $P_{i}$ is the output of generating unit $i$.

On the other hand, the capacities of the generating units can be expressed as

$$
P_{i, \min } \leq P_{i}^{t} \leq P_{i, \max } \quad \forall i,
$$

where $P_{i, \min }$ is the minimum load generating unit $i$ which can operate efficiently, $P_{i, \max }$ is the maximum load generating unit $i$ which can operate efficiently, and $P_{i}^{t}$ is the output of generating unit $i$ for time interval $t$. In the UC problem, the optimization model is slightly modified. UC has the same prime objective function which is to minimize total generation costs but this now includes start-up and shutdown costs since it assumes that generators are offline. UC can be also considered as a stochastic problem since it considers the needed demand for time interval $t$ for the planning horizon $T$. The optimization problem now minimizes the costs of generating power including the start-up and shutdown cost of generating units at a given interval. The objective function is now modelled as

$$
\min \sum_{t=1}^{T} \sum_{i=1}^{N}\left[F_{i}\left(P_{i}^{t}\right)+\text { Start-up or shutdown cost of } i \text { at interval } t\right] U_{i}^{t}
$$

where $P_{i}^{t}$ is the load required of generating unit $i$ at interval $t$ and $U_{i}^{t}$ is the commitment state of generating unit $i$ at interval t. $U_{i}^{t}$ is a binary variable where 1 is for online state and 0 is for offline state. For the basic UC model, the constraints of the ELD are modified to represent the time intervals generating units which are operating. $P_{i}^{t}$ is used in UC instead of $P_{i}$ to take into account the specified planning time horizon present in the UC problem. This differentiates the UC problem from the ELD problem:

$$
\begin{aligned}
P_{D}^{t}+P_{L}^{t} & =\sum_{i=1}^{N} P_{i}^{t} \quad \forall t, \\
P_{\min , i}^{t} & \leq P_{i}^{t} \leq P_{\max , i}^{t} \quad \forall i, t .
\end{aligned}
$$

Ramp rates are taken into account in UC since generating units have different rates as to how fast it could change its load. The ramp-up and ramp-down limits are represented as follows:

$$
\begin{aligned}
& P_{i}^{t-1}-P_{i}^{t} \leq \mathrm{DR}_{i}, \text { if power generation decreases, } \\
& P_{i}^{t}-P_{i}^{t-1} \leq \mathrm{UR}_{i} \text {, if power generation increases, }
\end{aligned}
$$

where $P_{i}^{t-1}$ is previous hour power generation of the $i$ th unit. $\mathrm{UR}_{i}$ and $\mathrm{DR}_{i}$ are the upper and down ramp rate limits of the $i$ th unit, respectively. Upper ramp rate is the rate of increase in the load of the generating unit. Down ramp rate is the rate of decrease of the load of the generating unit. Spinning 
reserve constraint defines the available minimum reserve that a certain plant must have. Spinning reserve is defined as the load that can be dispatched immediately. It can be dispatched immediately since the spinning reserve is the excess capacity of a generating unit that has not yet been dispatched. This constraint is defined as

$$
\begin{aligned}
r_{i} & \leq\left(P_{\max , i}-P_{i}\right) \quad \forall i, \\
\mathrm{SP} & =\sum_{i=1}^{N} r_{i},
\end{aligned}
$$

where $r_{i}$ is the excess capacity of a generating unit $i$ that has not yet been utilized. SP is the total excess capacity of the firm; otherwise it is known as spinning reserve.

\section{Case Study}

4.1. Case Information. The UC optimization problem was applied at a power plant in central Philippines, particularly in Cebu. This power plant is located in an export processing zone and is a subsidiary of a large energy and power firm in the Philippines. It a peaking diesel-fired power plant with a nameplate capacity $50 \mathrm{MW}$ and a dependable net capacity of $43 \mathrm{MW}$. It is operating for little over 17 years with an annual project cost of Php $1.7 \mathrm{~B}$, approximately equal to US\$ $38 \mathrm{M}$ and total investment of US\$ $1.9 \mathrm{M}$. It was financed through various means, that is, a combination of debt and equity finances over time. It currently employs 47 regular employees and a number of contractual and subcontractual employees. It supplies $22 \mathrm{MW}$ and $5 \mathrm{MW}$ to two major customers which are firms in the vicinity of the export processing zone. The rest of the generated power is sold to wholesale electricity spot market (WESM). The case firm has four diesel-fired engines type 16V 52/55 A diesel engine, manufactured by MAN B\&W 1983 in Augsburg, Germany. Its bore and stroke are measured to be $520 \mathrm{~mm} / 550 \mathrm{~mm}$. Its operation cycle is 4 -stroke, single acting. The four engines have a nameplate rating of $12,824 \mathrm{KW} /$ unit and speed of $450 \mathrm{rpm}$, a mean effective pressure of $18.3 \mathrm{BAR}$, a mean piston speed of $8.25 \mathrm{~m} / \mathrm{s}$, and firing pressure of $130 \mathrm{BAR}$. It is installed with a turbocharger by MAN B\&W, type NA 57 that has a mode of supercharging that is constant pressure. Diesel generator 1(DG1) that has output of $P_{1}$ was commissioned last February 1, 1998. Diesel generator 2 (DG2) that has output of $P_{2}$ was commissioned last January 16, 1998. Diesel generator 3 (DG3) that has output of $P_{3}$ was commissioned last January 3, 1998. Diesel generator 4 (DG4) that has output of $P_{4}$ was commissioned last December 25, 1998.

The ideal conditions of the plant are as follows:

Maximum ambient temperature: $38^{\circ} \mathrm{C}$.

Minimum ambient temperature: $18^{\circ} \mathrm{C}$.

Average relative humidity: $80 \%$.

Altitude above mean sea level: $7.6 \mathrm{~m}$.

Fuel heating value: $17,300 \mathrm{Btu} / \mathrm{lb}$.

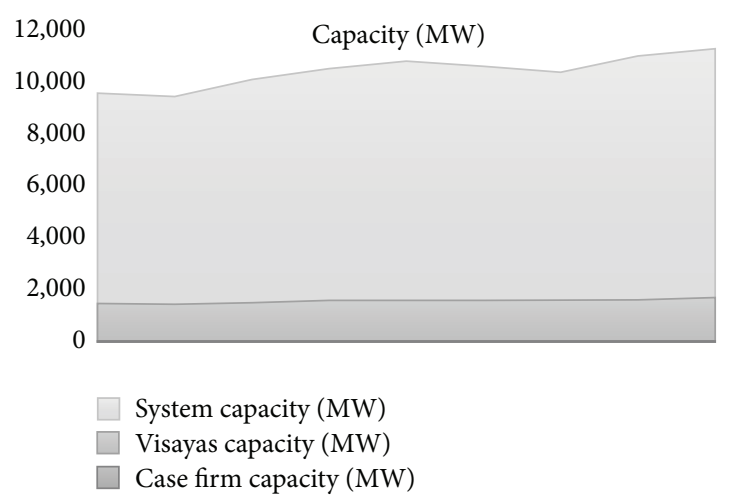

FIGURE 1: Capacity comparison representation.

With the following conditions, the plant has the following:

Gross rated capacity: 49,600 KW (49.6 MW $\approx 50 \mathrm{MW})$. Gross dependable capacity: 45,500 KW (45.5 MW).

Net dependable capacity: 43,000 KW (43.0 MW).

Specific fuel consumption at ISO condition: $187 \mathrm{gm} /$ KWh.

Net heat rate at site condition: 8,626 Btu/KWh.

Each engine is attached to a generator type SAMB Brushless AC Generator made by Ideal Electric Company with fram M-10-42 and serial numbers 931093-01-04. It has a power output of 12,400 KW, KVA rating 15,500 KVA, voltage 13,800 Volts, speed $450 \mathrm{rpm}$, and current of $648 \mathrm{amps}$. It is a 3-phase, 6-wire configuration, with a frequency of $60 \mathrm{~Hz}$ and power factor of 0.8 . It is classified as a continuous duty generator, with Class $\mathrm{F}$ insulation and a temperature rise of $100^{\circ} \mathrm{C}$.

The plant is connected to the Luzon-Visayas grid through the Cebu-Negros line and Cebu-Leyte-Samay line. The plant is identified in the grid as 5EAUC_G01 and is connected through Mactan. The capacity and demand of energy are taken to be the maximum capacity and demand per month. The system capacity is the total capacity the Luzon-Visayas grid can accommodate. It is taken to be the maximum energy all the plants have offered at an interval in a month. There is no inclusion of the Mindanao grid since it is not yet connected to the Luzon-Visayas grid. The capacity of the Visayas grid is taken to be the maximum energy all plants in the Visayas have offered. The contribution of the studied plant in the Visayas capacity is only $43 \mathrm{MW}$ since $43 \mathrm{MW}$ is the net dependable output of the plant. Figure 1 shows the capacity map of the case firm in relation to the Visayas capacity and the system capacity in a span of eight months in 2015. It can be shown that the case firm capacity is evidently small.

The actual demand per month is taken to be the peak demand that was recorded at that month. The demand is taken to the amount of power (MW) that was sold. Figure 2 shows the demand map of the case firm in relation to the system demand and the Visayas demand.

It can be observed in Figure 2 that the case firm's market share compared to the whole systems' demand and 


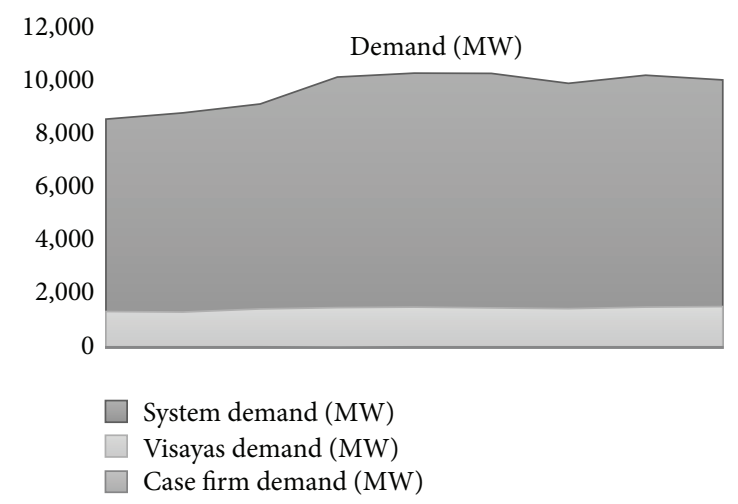

Figure 2: Demand comparison representation.

the Visayas' demand is very minimal. Thus, the case firm can be considered as a $50 \mathrm{MW}$ peaking power plant which is a small power firm. The dispatch decisions of the case firm are based on the priority list method in conjunction with the Merit-Order Loading method. For the unit commitment the plant has the priority list; it is where generators are prioritized based on running hours. The committed units through the priority list method are to be dispatched to its maximum capacity before committing another unit next in the priority list. This is referred to as the Merit-Order method.

Demand requirement forecast is usually done a day ahead. Since the case firm is a small power plant, it can purchase power from the market to supply relatively small demand for a particular time interval. Currently, the purchase decision depends on the actual demand for a given time interval, that is, hour, and the current market price of power.

4.2. General Procedure. In general, the procedure of carrying out the research problem is detailed as follows.

(1) Input fuel and output power quantities are obtained from the case firm. The gross input (Php) per generating unit is plotted against its net power output (MW). Second-degree curve fitting, as shown in (2), is done for each generating unit to determine the function relating power and input fuel cost. Since the case firm has four generating units, four curves are then generated. These functions become input to (1) and eventually (5). Since start-up and shutdown costs are negligible, these are not reflected in the cost function. With the presence of market participation, the cost function becomes

$$
\min \sum_{t=1}^{T}\left\{\left(\sum_{i=1}^{N}\left[F_{i}\left(P_{i}^{t}\right)\right] U_{i}^{t}\right)+c_{t} P_{N+1}^{t} U_{N+1}^{t}\right\},
$$

where $c_{t}$ is the cost or market price at time $t, P_{N+1}^{t}$ is the amount of power to be bought by the case firm from the market at time $t$, and $U_{N+1}^{t}$ is a binary variable where $U_{N+1}^{t}=0$ means that the case firm will not purchase from the market and $U_{N+1}^{t}=1$ means that the case firm must purchase from the market at time $t$. Due to the nonlinear property of $F_{i}\left(P_{i}^{t}\right) \forall i, t$ with the binary variables $U_{i}^{t} \forall i$, the optimization problem becomes a mixed-integer nonlinear programming (MINLP) problem. Equation (10) becomes the objective function of the optimization problem.

(2) Hourly power demand $\left(P_{D}^{T}\right)$ of the case firm is presented using (6). This is equal to the sum of all power output generated by all dispatched generating units including the market in a given time period, that is, hour. The power loss $\left(P_{L}\right)$ in (6) is negligible in the case firm. Thus,

$$
P_{D}^{t}=\sum_{i=1}^{N} P_{i}^{t}+P_{N+1}^{t}
$$

Equation (6) becomes the demand requirement constraint of the optimization problem.

(3) Minimum and maximum power limit of each power generation unit for all time periods are plugged into (7). The limit of $P_{N+1}^{t}$ is

$$
P_{N+1}^{t} \geq 0, \quad \forall t
$$

Equations (7) and (12) become the generation limits constraints of the optimization problem.

(4) Obtain the optimal solution of the optimization using Lingo ${ }^{\circledR}$ optimization software with global optimizer. The computation time is insignificant.

(5) Record the optimal cost for a particular time interval and prepare the optimal power generation schedule.

(6) Compare the optimal cost with the actual cost of the case firm. Compute the difference of theoretical costs which are obtained by the solving the MINLP UC problem and the actual costs of the case firm.

\section{Results and Discussion}

To obtain the fuel cost curves of the generating units, the fuel consumption per generating unit in one hour at certain loading (MW) intervals, from the minimum to the maximum, was recorded. The product of the price (Php) of fuel per liter (L) and the volume of fuel per hour (Php/h) was plotted against the loading. Figures 3-6 represent the cost functions DG1 to DG4, respectively. The coefficient of determination $\left(R^{2}\right)$ and the least-squares function $y=f(x)$ were also reported in Figures 3-6.

For DG1, results for the curve are shown in Figure 3. The vertical axis represents the output in monetary unit, that is, Php, while the horizontal axis is the input in MW. This is also true for Figure 4 through Figure 6. The function $F_{1}\left(P_{1}\right)=$ $-6.8264 P_{1}^{2}+2995 P_{1}+3925.4$ follows the one presented in (2) with $R^{2}=0.99424$.

For DG2, the results for the curve are as follows: $F_{2}\left(P_{2}\right)=$ $-82.1 P_{2}{ }^{2}+3868.9 P_{2}+2458.6$ also follows the one presented in (2) with $R^{2}=0.99647$.

For DG3, the results for the curve are as follows: $F_{3}\left(P_{3}\right)=$ $-28.13 P_{3}{ }^{2}+3207.9 P_{3}+3591.7$ with $R^{2}=0.99898$.

Lastly, for DG4, the results are as follows: $F_{4}\left(P_{4}\right)=$ $11.906 P_{4}^{2}+2911.7 P_{4}+3626.4$ and $R^{2}=0.99709$.

The hourly demand $P_{D}^{t}$ is taken from the actual dispatch schedule provided by the case firm for a span of one month, 24 hours a day. Equation (11) takes the form of $P_{D}^{t}=\sum_{i=1}^{4} P_{i}^{t}+$ 

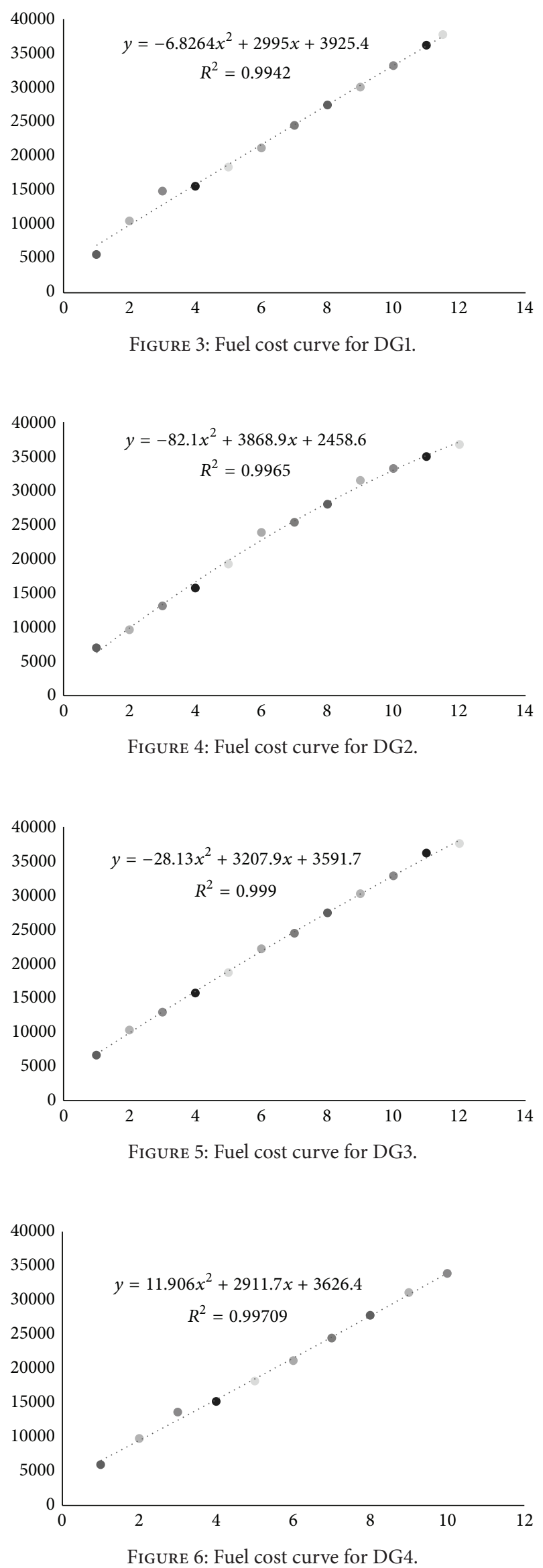

$P_{5}^{t}$. There is no stated system loss $P_{L}$ since the energy does not pass a transmission line. Also the measurement of the output was taken directly from the main source; hence loss is minimal and negligible. The form of (7) for DG1 is $6 \leq$ $P_{1}^{t} \leq 11.1, \forall t$. The form of (7) for DG2 is $6 \leq P_{2}^{t} \leq$ 11.0, $\forall t$. The form of (7) for DG3 is $6 \leq P_{3}^{t} \leq 11.5, \forall t$. The form of (7) for DG4 is $6 \leq P_{4}^{t} \leq 11.1, \forall t$. The minimum load for all generators is pegged at $6 \mathrm{MW}$ since it is in this loading schedule that the generators emit less pollutants and are efficient in burning fuel. Although they have the same engine types, they have different maximum limits due to their differences in running hours and parts replaced. There is no calculated start-up or shutdown costs. They are not included in the computations since the start-up and shutdown costs for the plants diesel engines are instantaneous and thus negligible. Also ramp rates are not considered since they are not applicable for the operation of the case firm. The case firm can easily and instantaneously ramp up or ramp down their loadings. Spinning reserve is not calculated since the plant and the Philippine market do not use it. There are no restrictions with regard to the market as to how much a plant's spinning reserve should be on any given interval.

The MINLP problem for the case firm is shown in the following:

$$
\begin{array}{ll}
\min & \sum_{t=1}^{T}\left\{\left(\sum_{i=1}^{N}\left[F_{i}\left(P_{i}^{t}\right)\right] U_{i}^{t}\right)+c_{t} P_{N+1}^{t} U_{N+1}^{t}\right\} \\
\text { s.t. } & P_{D}^{t}=\sum_{i=1}^{N} P_{i}^{t}+P_{N+1}^{t}, \quad \forall t \\
& P_{\min , i}^{t} \leq P_{i}^{t} \leq P_{\max , i}^{t}, \quad \forall i, t \\
& P_{N+1}^{t} \geq 0, \quad \forall t .
\end{array}
$$

Using Lingo optimization software with the historical $P_{D}^{t}$ values provided by the case firm, a sample 24 -hour dispatch schedule with 3-hour interval is shown in Table 1. For instance, the 16-18 interval shows that $11 \mathrm{MW}, 9.28 \mathrm{MW}$, and $6 \mathrm{MW}$ must be generated by DG2, DG3, and DG4, respectively, with $24.16 \mathrm{MW}$ being bought from the market (WESM). The optimum cost for this schedule is Php $124,795.60$, approximately equal to US\$ $2,773.24$ with 1 US\$ $=\mathrm{Php} 45$. However, the recorded cost of the case firm on this interval is Php 173,906.61 (US\$ 3,864.59) as shown in Table 1. The difference (actual cost - optimum cost) is Php 49,111.01 (US\$ 1,091.36). With a record of 29 days, the MINLP model is run to complete the analysis. Table 2 shows the sample daily dispatch schedule. It is observable that the disparity of costs, that is, optimal and actual costs, is significant. Finally, Table 3 presents the overall results in a month.

Table 3 shows that the optimum cost of the month using the UC MINLP problem should have been Php 11,928,513.05 (US\$265,078.07) while the recorded cost for the month was Php 16,376,268.41 (US\$363,917.08). This makes up the difference of Php 4,447,755.36 (US\$ 98,839.01). This difference comprises approximately $27 \%$ of the actual monthly cost. Figure 7 illustrates the summary of weekly cost differences. 
TABLE 1: Sample of 24-hour dispatch schedule.

\begin{tabular}{|c|c|c|c|c|c|c|c|c|c|}
\hline \multirow{2}{*}{ Interval } & \multicolumn{9}{|c|}{ Generator (load) } \\
\hline & $1(\mathrm{MW})$ & 2 (MW) & $3(\mathrm{MW})$ & $4(\mathrm{MW})$ & WESM (MW) & Demand (MW) & Total cost (Php) & Actual cost (Php) & Difference (Php) \\
\hline $1-3$ & - & - & - & - & - & - & - & - & - \\
\hline $4-6$ & - & - & - & - & - & - & - & - & - \\
\hline $7-9$ & - & - & - & - & 18.14 & 18.14 & $24,088.47$ & $53,007.70$ & $28,919.23$ \\
\hline $10-12$ & - & - & - & - & 36 & 36 & $64,754.16$ & $145,114.37$ & $80,360.21$ \\
\hline $13-15$ & - & - & - & - & 77.74 & 77.74 & $186,172.00$ & $306,765.78$ & $120,593.78$ \\
\hline $16-18$ & - & 11 & 9.28 & 6 & 24.16 & 50.44 & $124,795.60$ & $173,906.61$ & $49,111.01$ \\
\hline $19-21$ & 7.6 & - & 11.5 & - & 24.1 & 43.2 & $102,735.40$ & $155,361.20$ & $52,625.80$ \\
\hline $22-24$ & - & - & - & - & 10 & 10 & $13,553.60$ & $27,155.70$ & $13,602.10$ \\
\hline
\end{tabular}

TABLE 2: Sample of daily dispatch schedule.

\begin{tabular}{|c|c|c|c|c|c|c|c|c|c|}
\hline \multirow{2}{*}{ Day } & \multicolumn{9}{|c|}{ Generator (load) } \\
\hline & $1(\mathrm{MW})$ & $2(\mathrm{MW})$ & $3(\mathrm{MW})$ & $4(\mathrm{MW})$ & WESM (MW) & Demand (MW) & Total cost (Php) & Actual cost (Php) & Difference (Php) \\
\hline 1 & 7.60 & 11.00 & 20.78 & 6.00 & 190.14 & 235.52 & $516,099.23$ & $861,311.36$ & $345,212.13$ \\
\hline 2 & - & 22.00 & 21.36 & 6.00 & 190.90 & 240.25 & $577,580.07$ & $826,157.23$ & $248,577.16$ \\
\hline 3 & - & 55.00 & 42.50 & 6.00 & 119.30 & 222.80 & $576,724.88$ & $799,232.89$ & $222,508.01$ \\
\hline 4 & - & - & - & - & 152.00 & 152.00 & $137,587.94$ & $314,429.24$ & $176,841.30$ \\
\hline 5 & - & - & - & - & - & - & - & - & - \\
\hline 6 & - & - & - & - & - & - & - & - & - \\
\hline 7 & 14.37 & 33.00 & 11.00 & 12.00 & 176.50 & 246.87 & $508,505.66$ & $817,308.86$ & $308,803.20$ \\
\hline 8 & 11.10 & 44.00 & 43.50 & - & 186.04 & 284.64 & $800,760.58$ & $893,468.85$ & $92,708.27$ \\
\hline 9 & 6.40 & 44.00 & 53.50 & 12.00 & 169.98 & 285.88 & $831,577.92$ & $978,041.81$ & $146,463.89$ \\
\hline 10 & 11.10 & - & 20.00 & 6.00 & 249.34 & 286.44 & $627,515.56$ & $872,805.62$ & $245,290.06$ \\
\hline 11 & - & 11.00 & - & - & 129.00 & 140.00 & $286,158.43$ & $466,501.54$ & $180,343.11$ \\
\hline 12 & - & - & - & - & - & - & - & - & - \\
\hline 13 & - & 11.00 & - & - & 199.31 & 210.31 & $381,044.86$ & $670,454.24$ & $289,409.38$ \\
\hline 14 & - & 11.00 & - & - & 220.38 & 231.38 & $443,115.71$ & $636,757.35$ & $193,641.64$ \\
\hline 15 & - & 11.00 & - & - & 131.00 & 142.00 & $219,223.07$ & $468,133.91$ & $248,910.84$ \\
\hline 16 & - & 22.00 & - & - & 194.42 & 216.42 & $402,135.54$ & $567,306.37$ & $165,170.83$ \\
\hline 17 & - & - & - & - & 242.16 & 242.16 & $363,391.14$ & $594,183.21$ & $230,792.07$ \\
\hline 18 & - & 11.00 & - & - & 116.00 & 127.00 & $255,926.07$ & $416,199.68$ & $160,273.61$ \\
\hline 19 & - & - & - & - & - & - & - & - & - \\
\hline 20 & - & - & 11.50 & - & 213.90 & 225.40 & $385,745.60$ & $570,024.00$ & $184,278.40$ \\
\hline 21 & 8.90 & 44.00 & 31.90 & 6.42 & 169.16 & 260.38 & $549,674.20$ & $801,667.40$ & $251,993.20$ \\
\hline 22 & - & - & - & - & 251.08 & 251.08 & $383,628.67$ & $600,849.85$ & $217,221.18$ \\
\hline 23 & - & - & - & - & 220.50 & 220.50 & $358,822.83$ & $579,351.73$ & $220,528.90$ \\
\hline 24 & - & 11.00 & - & - & 230.22 & 241.22 & $438,375.30$ & $650,212.15$ & $211,836.85$ \\
\hline 25 & 7.19 & 22.00 & - & 6.00 & 119.00 & 154.19 & $336,915.39$ & $607,571.60$ & $270,656.21$ \\
\hline 26 & - & - & - & - & - & - & - & - & - \\
\hline 27 & 47.50 & 88.00 & 86.20 & 12.00 & 78.30 & 312.00 & $959,102.37$ & $1,124,398.40$ & $165,296.03$ \\
\hline 28 & 28.04 & 132.50 & 97.78 & 24.00 & 37.88 & 320.20 & $1,039,227.83$ & $1,259,901.12$ & $220,673.29$ \\
\hline
\end{tabular}

TABLE 3: Sample of weekly dispatch schedule.

\begin{tabular}{|c|c|c|c|c|c|c|c|c|c|}
\hline \multirow{2}{*}{ Week } & \multicolumn{9}{|c|}{ Generator (load) } \\
\hline & $1(\mathrm{MW})$ & $2(\mathrm{MW})$ & $3(\mathrm{MW})$ & $4(\mathrm{MW})$ & WESM (MW) & Demand (MW) & Total cost (Php) & Actual cost (Php) & Difference (Php) \\
\hline 1 & 21.97 & 121 & 95.64 & 30 & 828.84 & $1,097.44$ & $2,316,497.78$ & $2,801,130.72$ & $484,632.94$ \\
\hline 2 & 28.6 & 121 & 117 & 18 & $1,154.05$ & $1,438.65$ & $3,370,173.06$ & $4,698,580.92$ & $1,328,407.86$ \\
\hline 3 & 8.9 & 88 & 43.4 & 6.42 & $1,066.64$ & $1,213.36$ & $2,176,095.62$ & $3,252,604.52$ & $1,076,508.90$ \\
\hline 4 & 101.49 & 374.5 & 245.28 & 60.26 & 956.98 & $1,738.50$ & $4,065,746.59$ & $5,623,952.25$ & $1,558,205.66$ \\
\hline & & & & Total & & & $11,928,513.05$ & $16,376,268.41$ & $4,447,755.36$ \\
\hline
\end{tabular}




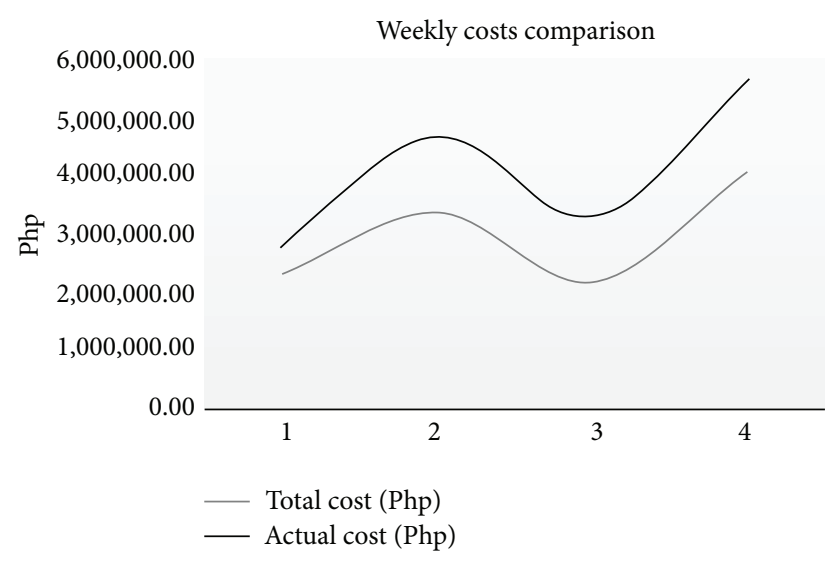

Figure 7: Weekly costs comparison.

The reported cost differences are due to the optimum schedule generated from the UC problem which provides a more sound technical mathematical formulation of the problem. The developed model utilized the result of the MINLP problem for the UC problem through the branch and bound algorithm and the Lagrangian relaxation method by way of presenting the problem in the context of KarushKuhn-Tucker (KKT) conditions which is considered as a general approach in solving nonlinear constrained optimization problem. See Ocampo et al. [39] for a sample computational approach of the KKT conditions. The actual dispatch of the company utilizes the priority list method with Merit-Order Loading which may not provide optimal or least cost. The developed optimization model for the UC problem can better determine the proper schedule of load to be generated with the least fuel cost. It also provides a guideline on the optimum amount of power to be purchased from the market pool. Using the UC problem as the platform, the case firm could benefit annual estimated savings of US\$ 470,500.

\section{Conclusion}

Unit commitment (UC) problem is a fundamental problem in power generation systems in providing a dispatch schedule of power generating units that minimizes generation cost in terms of fuel. However, for power generation firms especially small firms situated in developing countries, UC problem is poorly understood if not implemented. This study highlights the application of UC problem in a small power plant in the Philippines with the aim of illustrating the use of UC problem and determining cost disparities between actual and computed values. Results show that it is beneficial for small peaking plants to adopt UC-based models when determining the loading schedule for generating units to achieve minimum cost. This is also applicable when the firm has the option of purchasing power from the market pool. The results generated provide a loading strategy which shows better results in terms of costs than the current method of the case firm. It also shows that a good estimate of cost disparity for not adopting the UC problem is at $27 \%$ which could be possibly translated to savings for the firm. Thus,
UC-based models provide a reliable procedure for scheduling power generation units which would yield the least cost. Future research directions include the incorporation of other relevant constraints to the model such as running hours and maintenance schedules.

\section{Competing Interests}

The authors declare that they have no competing interests.

\section{Acknowledgments}

The authors are grateful for the support provided by the University of San Carlos in terms of resource use. Likewise, the authors acknowledge the support extended by the case firm.

\section{References}

[1] L. Raju, R. S. Milton, S. Suresh, and S. Sankar, "Reinforcement learning in adaptive control of power system generation," in Proceedings of the International Conference on Information and Communication Technologies, vol. 48, pp. 202-209, Kochi, India, 2015.

[2] S. Najafi and J. Purjamal, "A new heuristic algorithm for unit commitment problem," Energy Procedia, vol. 14, pp. 2005-2011, 2012.

[3] X. Xia and A. M. Elaiw, "Optimal dynamic economic dispatch of generation: a review," Electric Power Systems Research, vol. 80, no. 8, pp. 975-986, 2010.

[4] T. Senjyu, K. Shimabukuro, K. Uezato, and T. Funabashi, "A fast technique for unit commitment problem by extended priority list," IEEE Transactions on Power Systems, vol. 18, no. 2, pp. 882888, 2003.

[5] S. Virmani, E. C. Adrian, K. Imhof, and S. Mukherjee, "Implementation of a Lagrangian relaxation based unit commitment problem," IEEE Transactions on Power Systems, vol. 4, no. 4, pp. 1373-1380, 1989.

[6] Y. Wang, J. Yan, J. Li, Z. Li, and W. Zhang, "A new model of economic dispatch considering energy conservation and environmental protection in electricity market," Energy Procedia, vol. 17, pp. 1769-1777, 2012.

[7] R. Storn and K. Price, "Differential evolution-a simple and efficient adaptive scheme for global optimization over continuous spaces," Technology Report TR-95-012, International Computer Science Institute (ICSI), Berkeley, Calif, USA, 1997.

[8] A. J. Wood and B. F. Wollenburg, Power Generation Operation and Control, John Wiley \& Sons, New York, NY, USA, 1996.

[9] C. A. Coronado, M. R. Figueroa, and C. A. Roa-Sepulveda, "A reinforcement learning solution for the unit commitment problem," in Proceedings of the 47th International Universities Power Engineering Conference, pp. 1-6, IEEE, London, UK, September 2012.

[10] M. H. Sendaula, S. K. Biswas, A. Eltom, C. Parten, and W. Kazibwe, "Simultaneous solution of unit commitment and dispatch problems using artificial neural networks," International Journal of Electrical Power and Energy Systems, vol. 15, no. 3, pp. 193-199, 1993.

[11] B. Saravanan, S. Das, S. Sikri, and D. P. Kothari, "A solution to the unit commitment problem-a review," Frontiers in Energy, vol. 7, no. 2, pp. 223-236, 2013. 
[12] E. A. Bakirtzis, P. N. Biskas, D. P. Labridis, and A. G. Bakirtzis, "Multiple time resolution unit commitment for short-term operations scheduling under high renewable penetration," IEEE Transactions on Power Systems, vol. 29, no. 1, pp. 149-159, 2014.

[13] F.-J. Heredia, M. J. Rider, and C. Corchero, "Optimal bidding strategies for thermal and generic programming units in the day-ahead electricity market," IEEE Transactions on Power Systems, vol. 25, no. 3, pp. 1504-1518, 2010.

[14] R. Laia, H. M. I. Pousinho, R. Melíco, and V. M. F. Mendes, "Selfscheduling and bidding strategies of thermal units with stochastic emission constraints," Energy Conversion and Management, vol. 89, pp. 975-984, 2015.

[15] S. Subramanian, M. Abirami, and S. Ganesan, "Reliable/costeffective maintenance schedules for a composite power system using fuzzy supported teaching learning algorithm," IET Generation, Transmission and Distribution, vol. 9, no. 9, pp. 805-819, 2015.

[16] P. Rodilla, S. Cerisola, and C. Batlle, "Modeling the major overhaul cost of gas-fired plants in the unit commitment problem," IEEE Transactions on Power Systems, vol. 29, no. 3, pp. 1001-1011, 2014.

[17] L. Tang, P. Che, and J. Wang, "Corrective unit commitment to an unforeseen unit breakdown," IEEE Transactions on Power Systems, vol. 27, no. 4, pp. 1729-1740, 2012.

[18] G. Morales-España, J. M. Latorre, and A. Ramos, "Tight and compact MILP formulation of start-up and shut-down ramping in unit commitment," IEEE Transactions on Power Systems, vol. 28, no. 2, pp. 1288-1296, 2013.

[19] C. Wang and S. M. Shahidehpour, "Ramp-rate limits in unit commitment and economic dispatch incorporating rotor fatigue effect," IEEE Transactions on Power Systems, vol. 9, no. 3, pp. 1539-1545, 1994.

[20] N. Troy, D. Flynn, M. Milligan, and M. O’Malley, "Unit commitment with dynamic cycling costs," IEEE Transactions on Power Systems, vol. 27, no. 4, pp. 2196-2205, 2012.

[21] V. K. Jadoun, N. Gupta, K. R. Niazi, and A. Swarnkar, "Modulated particle swarm optimization for economic emission dispatch," International Journal of Electrical Power and Energy Systems, vol. 73, pp. 80-88, 2015.

[22] J. Di, M. Fei, L. Wang, and W. Wu, "Multi-objective optimization for economic emission dispatch using an improved multi-objective binary differential evolution algorithm," Energy Procedia, vol. 61, pp. 2016-2021, 2014.

[23] R. Arul, S. Velusami, and G. Ravi, "A new algorithm for combined dynamic economic emission dispatch with security constraints," Energy, vol. 79, pp. 496-511, 2015.

[24] N. I. Nwulu and X. Xia, "Multi-objective dynamic economic emission dispatch of electric power generation integrated with game theory based demand response programs," Energy Conversion and Management, vol. 89, pp. 963-974, 2015.

[25] G. P. Granelli, M. Montagna, G. L. Pasini, and P. Marannino, "Emission constrained dynamic dispatch," Electric Power Systems Research, vol. 24, no. 1, pp. 55-64, 1992.

[26] Z. Zhou and A. Botterud, "Dynamic scheduling of operating reserves in co-optimized electricity markets with wind power," IEEE Transactions on Power Systems, vol. 29, no. 1, pp. 160-171, 2014.

[27] S. J. Plathottam and H. Salehfar, "Unbiased economic dispatch in control areas with conventional and renewable generation sources," Electric Power Systems Research, vol. 119, pp. 313-321, 2015.
[28] K. Geetha, V. Sharmila Deve, and K. Keerthivasan, "Design of economic dispatch model for Gencos with thermal and wind powered generators," International Journal of Electrical Power and Energy Systems, vol. 68, pp. 222-232, 2015.

[29] H. Zhong, Q. Xia, Y. Xia et al., "Integrated dispatch of generation and load: a pathway towards smart grids," Electric Power Systems Research, vol. 120, pp. 206-213, 2015.

[30] A. Khodaei, M. Shahidehpour, and S. Bahramirad, "SCUC with hourly demand response considering intertemporal load characteristics," IEEE Transactions on Smart Grid, vol. 2, no. 3, pp. 564-571, 2011.

[31] I. T. Papaioannou, A. Purvins, and E. Tzimas, "Demand shifting analysis at high penetration of distributed generation in low voltage grids," International Journal of Electrical Power and Energy Systems, vol. 44, no. 1, pp. 540-546, 2013.

[32] N. Nwulu, X. Xia, and J. Zhang, "Determining the optimal incentive and number of retrofits for a demand response program in South Africa," in Proceedings of the 5th International Conference on Applied Energy (ICAE '13), pp. 1-4, Pretoria, South Africa, 2013.

[33] F. H. Magnago, J. Alemany, and J. Lin, "Impact of demand response resources on unit commitment and dispatch in a day-ahead electricity market," International Journal of Electrical Power and Energy Systems, vol. 68, pp. 142-149, 2015.

[34] H. Wu, M. Shahidehpour, and A. Al-Abdulwahab, "Hourly demand response in day-ahead scheduling for managing the variability of renewable energy," IET Generation, Transmission and Distribution, vol. 7, no. 3, pp. 226-234, 2013.

[35] V. K. Tumuluru, Z. Huang, and D. H. K. Tsang, "Integrating price responsive demand into the unit commitment problem," IEEE Transactions on Smart Grid, vol. 5, no. 6, pp. 2757-2765, 2014.

[36] T. Ackermann, G. Andersson, and L. Söder, "Distributed generation: a definition," Electric Power Systems Research, vol. 57, no. 3, pp. 195-204, 2001.

[37] P. Kayal, T. Bhattacharjee, and C. Chanda, "Planning of renewable DGs for distribution network considering load model: a multi-objective approach," Energy Procedia, vol. 54, pp. 85-96, 2014.

[38] A. Safdarian, M. Fotuhi-Firuzabad, and M. Lehtonen, "Integration of price-based demand response in DisCos' short-term decision model," IEEE Transactions on Smart Grid, vol. 5, no. 5, pp. 2235-2245, 2014.

[39] L. Ocampo, E. Clark, and A. Liggayu, "Lot size formulation minimizing makespan with transactional and movement times," Advances in Industrial Engineering and Management, vol. 3, no. 2, pp. 13-18, 2014. 


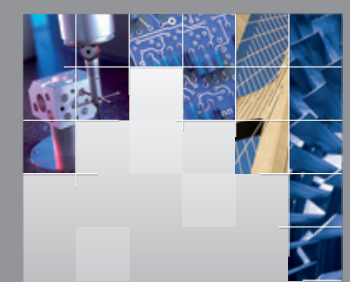

\section{Enfincering}
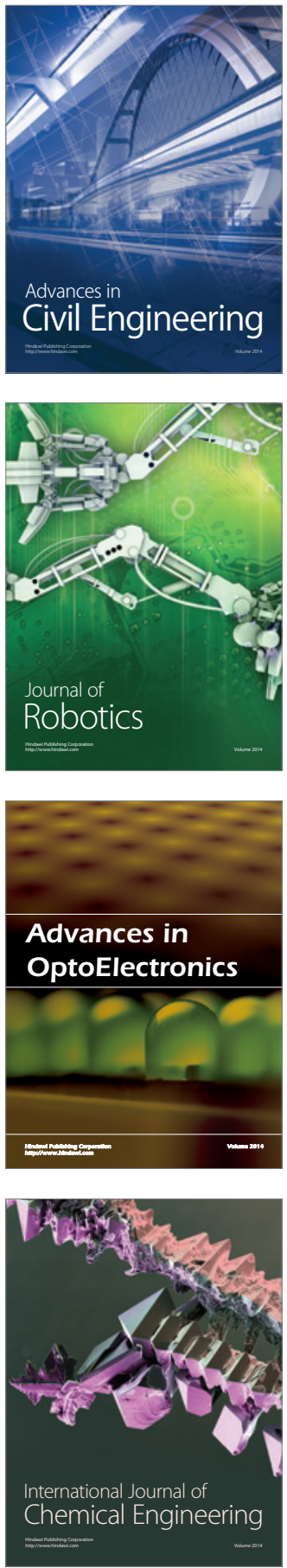

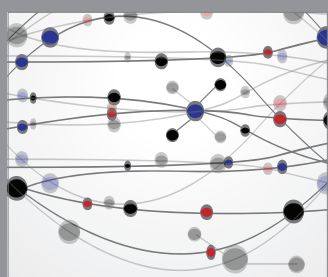

The Scientific World Journal

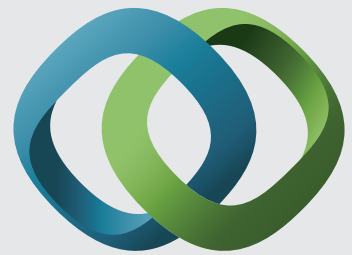

\section{Hindawi}

Submit your manuscripts at

http://www.hindawi.com
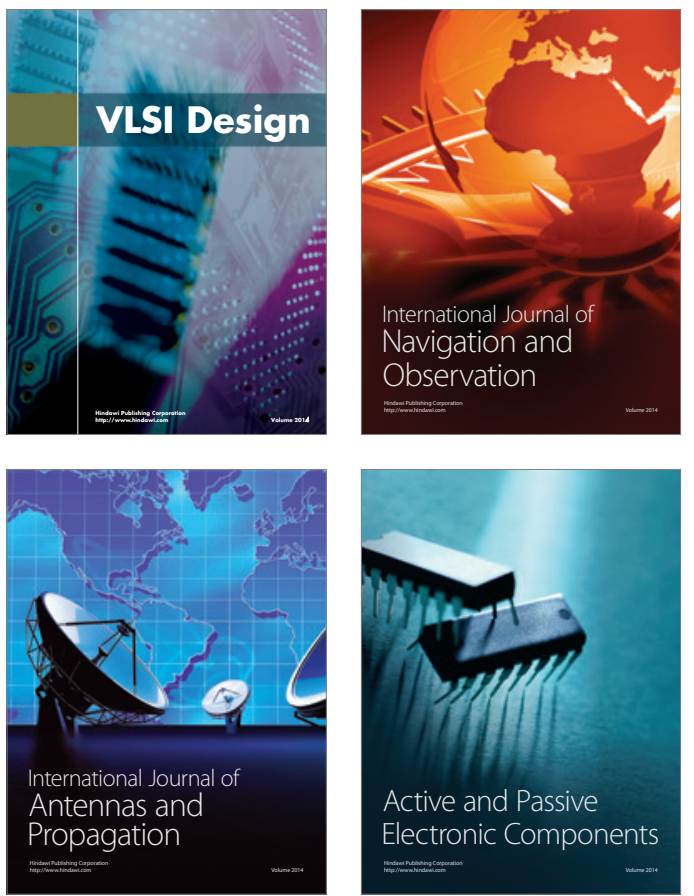
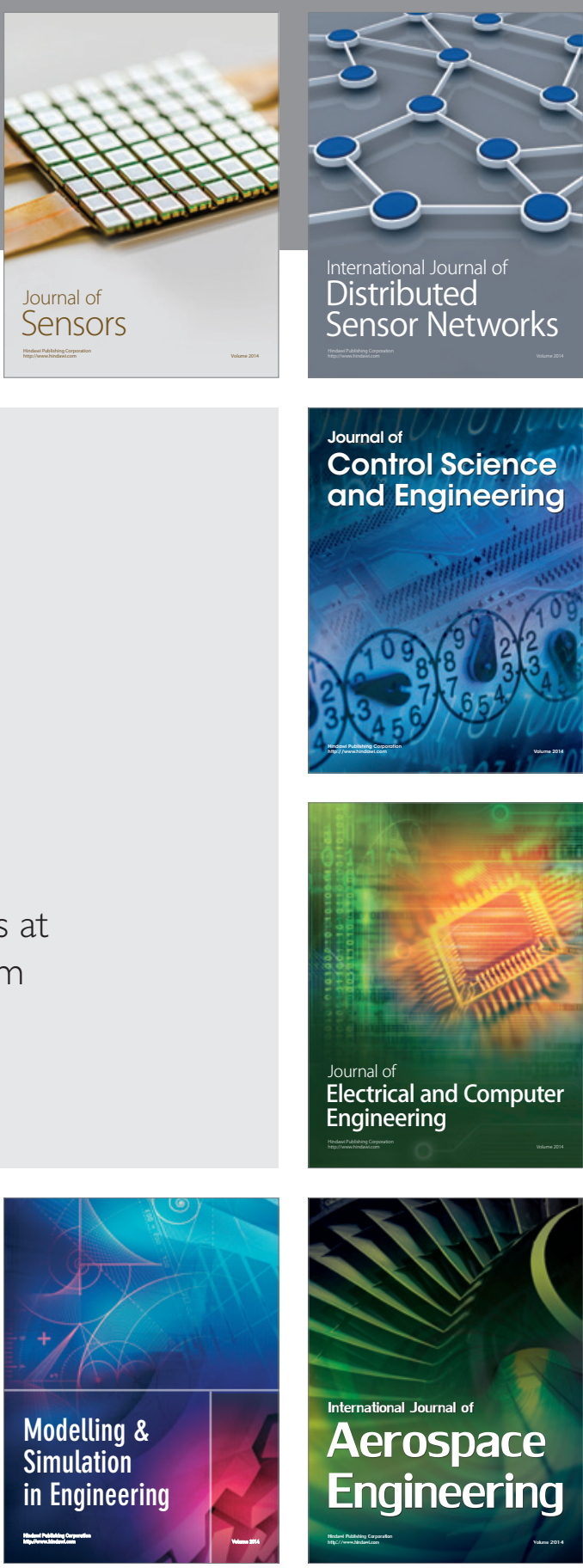

International Journal of

Distributed

Sensor Networks

Journal of

Control Science

and Engineering
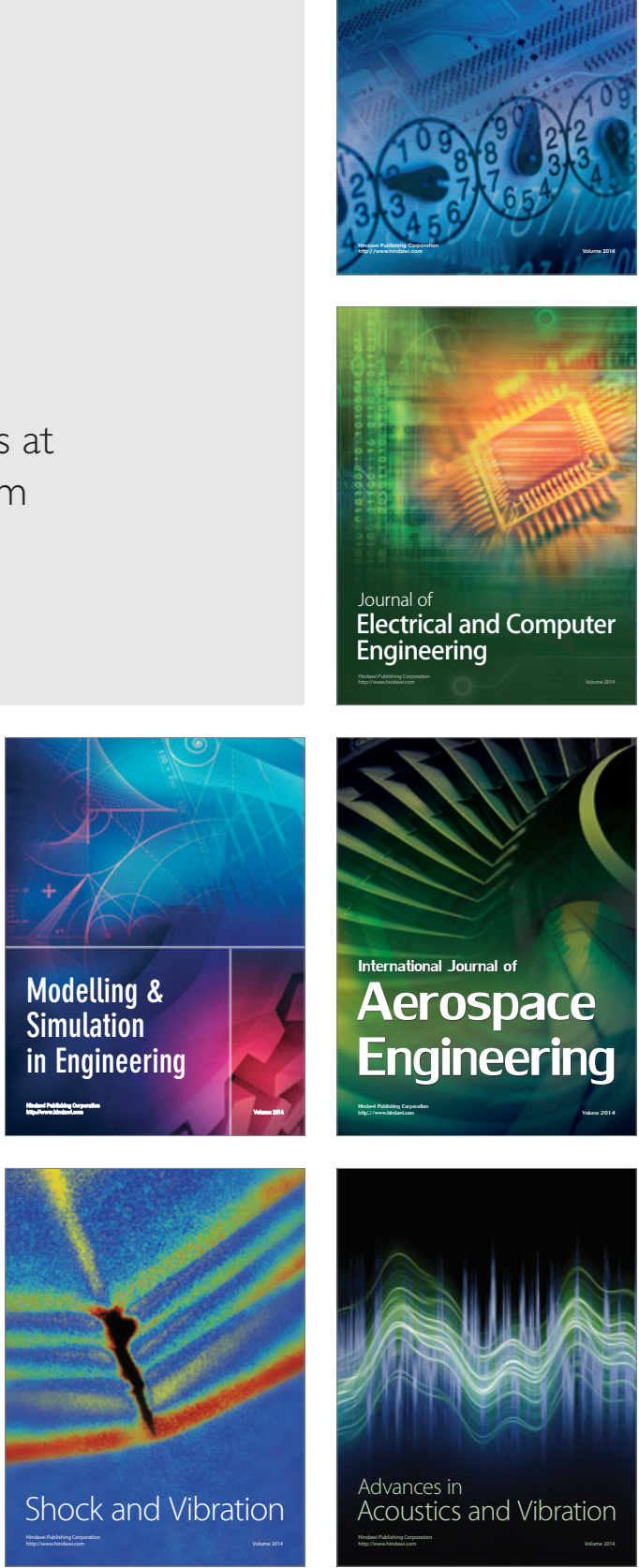